\title{
NOTAS DE BIBLIOGRAFIA E DE CRÍTICA
}

\author{
ANTENOR NASCENTES - O IDIOMA NACIONAL - Livraria Acadêmica, Rio, \\ 1960, 280 págs.
}

E digna de elogios a iniciativa da Livraria Acadêmica, do Rio de Janeiro, de reeditar um livro já clássico da filologia portuguêsa, O Idioma Nacional, do grande Mestre brasileiro Antenor Nascentes. Tendo sido o livro já há muito tempo esgotado e sendo a sua consulta indispensável para todos os que se interessam pelo portuguès, sua estrutura, evoluçāo e peculiaridades, representa a nova, já terceira edição do Idioma Nacional um verdadeiro acontecimento de grande importância. Os filólogos brasileiros mesmo deverão dizer - que significou e significa êste livro para a filologia e ensino do português no seu país. Mas o que pode dizer o abaixo-assinado, como estrangeiro, é que - Idioma Nacional é, no verdadeiro sentido da palavra, um livro ideal para todos os que, fora do Brasil e de Portugal, se interessam pela filologia e lingua portuguêsas. O Idioma Nacional contém todo o essencial que se deve saber do português, para dominá-lo bem e compreender a sua estrutura e evolução: elementos da gramática normativa (fonética, morfologia, sintaxe), uma breve, mas substanciosa gramática histórica, as noções principais do léxico português e do português no Brasil: e é talvez nos apêndices onde o Autor mais demonstrou a sua profunda compreensão pelas dificuldades que possa encontrar um brasileiro, um português ou um estrangeiro, aperfeiçoando ou aprendendo a lingua portuguêsa: nêles incluiu o $\mathrm{A}$. tudo em que tão freqüentemente se cometem erros (palavras de prosódia duvidosa, formação dos coletivos, dos adjetivos pátrios, dos femininos de substantivos em -ão, etc.)

O livro do Professor Nascentes, êste grande pioneiro da filologia portu. guêsa no Brasil e o primeiro romanista brasileiro em data que ganhou uma notável projeção fora do seu pais, está redigido - como, aliảs, todos os outros trabalhos do Mestre - de uma maneira clara, tornando-se assim muito fácil a sua conduta. E, pois, um livro acessivel, embora não deixe de ter uma base científica; um livro simples e, ao mesmo tempo, profundo, interessante e útil; numa palavra, um livro fundamental.

Zdenek Hampejs (Praha). 


\section{PAULO RÓNAI - A LÍNGUA FRANCESA - SUA EVOLUÇÃo E SUA ES.} TRUTURA - Editôra Delta S. A. Rio, s. d., 81 pp.

O escritor e filólogo brasileiro Paulo Rónai, catedrático de francês no Colégio-Padrão Pedro II, do Rio de Janeiro, escreveu para a Enciclopédia Delta-Larousse (Larousse português), publicada pela Editôra Delta Ș.A., do Rio de laneiro, uma sinopse da evoluçāo e estrutura da língua francesa. A separata dêste trabalho, que temos à mão, é um interessante opúsculo de 81 pp., de tamanho grande, contendo o essêncial que se deve saber sôbre a história e - estado atual da principal língua neolatina. $O$ que é de maior interêsse para um romanista (coincidindo êste interêsse, certamente, com o de todos os leitores, cuja língua materna é o português), é a constante e consequiente comparação que $\circ$ A. apresenta entre os fenômenos franceses e portuguêses. A consulta dêste opúsculo, destinado ao grande público, é de grande utilidade para todos os que querem ter a primeira informação sôbre as diferenças existentes entre os sistemas francês e português.

Zdenek Hampejs (Praha)

\section{DÁMASO ALONSO - POESIA ESPANHOLA (Ensaio de Métodos e Limites Esti- lísticos) - Rio, 1960, $471 \mathrm{pp}$.}

O Instituto Nacional do Livro, do Rio de Janerio, que, sob a direção de José Renato Santos Pereira, vem desenvolvendo uma atividade editorial de grande importância para a cultura brasileira, acaba de publicar o já famoso livro do poeta e crítico espànhol, Dámaso Alonso, Poesía española (Ensayo de métodos y límites estilísticos). Não pretendemos apresentar aqui uma resenha detalhada desta obra, que foi submetida a profundas análises por críticos muito mais competentes e que há muitos anos é já do conhecimento do público interessado (em 1957 publicou a Editorial Gredos, de Madrid, a sua 3a. edição). Queremos só assinalar nas páginas desta revista o notável fato de publicar-se esta obra, traduzida por Darcy Damasceno e dotada de um prefácio do $A$. para a edição brasileira, como o primeiro volume de uma nova série, lançada pelo Instituto e denominada: Biblioteca de Filologia Románica. $O$ nome do Prof. Celso Cunha, Catedrático da Universidade do Brasil, que está dirigindo a Biblioteca, é uma garantia, de que nela se publicarão obras bem e com bom gôsto escolhidas e que servirão para o desenvolvimento dos tão felizmente iniciados estudos das línguas e literaturas românicas no Brasil.

Zdenek Hampejs (Praha)

ADRIANO DA GAMA KURY - PEQUENA GRAMATICA Para a Explicação da Nova Nomenclatura Gramatical - Livraria Agir Editôra, Rio, 6.a èd., 1960. 141 págs.

PORTUGUES BÁSICO - GRAMÁTICA, ANTOLOGIA, EXERCICIOS, Livraria Agir Editóra, Rio, 1960, 286, págs. 
Não podemos deixar de chamar a atenção dos leitores para dois importantes manuais de português, cujo autor é o jovem lingüista brasileiro e uma das maiores esperanças da filologia nacional, Adriano da Gama Kury, Professor de Portuguess, por concurso, da Prefeitura do ex-Distrito Federal e da Escola Técnica Nacional e Professor de Português do Colégio Pedro II.

Cronològicamente primeira é a Pequena Cramática que, em pouco mais de um ano, atingiu seis ediçōes e a tiragem, excepcionalmente alta para o Brasil, de 50.000 exemplares. Quem tenha lido esta obra, não fica admirado do seu êxito. Ela merece a atenção do público pelo menos por duas razões. Primeiro, porque foi publicada alguns meses depois da aprovação oficial da nova nomenclatura gramatical brasileira, elaborada por um grupo de insignes filólogos e destinada a uniformizar e simplificar a terminologia usada nas gramáticas e livros didáticos no Brasil; por mais importante que seja a Nomenclatura (uma das poucas obras de equipe, realizadas até hoje na filologia do Brasil), não é mais do que uma enumeração - detalhada e precisa - de têrmos admitido para o uso nas gramáticas. Para a explicação desta nova Nomenclatura era preciso elaborar um livro que exemplificasse e esclarecesse todos os nomes que nela aparecem. "Na sua forma definitiva, é a NGB (=Nomenclatura Gramatical Brasileira) um esqueleto; e a finalidade dêste livrinho é torná-la corpo" elucida, acertadamente, o próprio autor da Pequena Gramática no prefácio a sua l.a ediçāo. Sabendo destas circunstâncias, nāo nos admiramos mais do interêsse que despertou a Pequena Gramática entre o grande público, obrigado a aprender, adotar e usar, na escola ou na sua profissāo, o novo sistema de têrmos gramaticais.

Mas o êxito da obra de Kury não reside só nas mencionadas circunstâncias que favoreceram a sua boa aceitaçāo. Reside, a nosso modo de ver, sobretudo nas suas qualidades e no método pelo qual foi elaborado. Esta obra ocupa cronològicamente, um dos primeiros lugares entre as gramáticas da língua portuguèsa, isentas de purismo e dotadas de um novo espírito didático. Os "gramáticos" que tanto mal fizeram no campo da filologia e lingüistica brasileira ("gramáticos" sem formação filológica ou amadores, desligados da vida e da língua atual e que tudo fizeram para adaptar o português de hoje aos moldes da língua arcaica, encontrando um prazer especial em ostentar a sua falsa erudiçāo em listas intermináveis de vocábulos livrescos, só raramente ou nunca usados e em registrar "erros" de sintaxe, se ela divergia das normas sintáticas usuais no tempo de Camōes ou Vieira), felizmente, no Brasil perdem terreno, que tanto tempo tinham dominado, e o Autor da Pequena Gramática contribuiu substancialmente para a vitória da nova e moderna corrente. $O$ que diferencia também esta gramática das existentes, é que ela não tem preocupação normativa, senão pretende conceituar fatos de gramática, de maneira que, em princípio, não apresenta regras de bem escrever, como o fazem os seus antecessores. A obra, além das partes em que tradicionalmente se divide a gramática (fonética, morfologia, sintaxe) contém um rico apéndice, no qual não falta nem um breve resumo da gramática histórica (que, segundo a nossa opi- 
niāo, valeria a pena ser publicada aparte, em livro especial) e que, fora disso, contém várias informaçôes, úteis, especialmente, aos professôres do curso primário e secundário, aos quais é, sobretudo, destinada.

A clareza e falta de caturrice distingue também a outra obra do Prof. Kury, Português Básico, adaptada ao programa de admissão ao ginásio. Não se trata de um "Basic Portuguese", como do título da obra se poderia supor. Trata-se de um livro que deve ministrar "as noções básicas de Português necessárias aos que desejam fazer, com fundamentos sólidos, um curso secundário proveitoso". Tanto como a Pequena Cramática reage também êste novo manual contra a "gramaticalização ôca de pura memorização", tem o caráter - no melhor sentido da palavra - prático e revela um grande talento do A. de sistematizar a matéria. Apesar de se tratar de um simples, não cabe dúvida que custou um grande trabalho, porque tanto na ordenação da matéria como na sua composição se vê que tudo foi bem pensado e que tudo se baseia numa longa experiência do Autor. Divergindo da maioria dos manuais, começa - Português básico pelas noções de Sintaxe, tendo esta novidade (cujo acêrto só a prática pode demonstrar) a finalidade de facilitar a compreensão de numerosos fatos da Morfologia que representa uma parte posterior do livro, sendo precedida ainda pelos capítulos dedicados à Fonética e à Ortografia. A segunda parte do livro é representada por uma antologia de textos, convenientes para a leitura na escola; a escolha foi muito cuidadosa e o comentário, que segue cada um dos trechos literários escolhidos, demonstra mais uma vez - grande carinho com que o A. preparou esta sua última obra publicada; a antologia, como é natural, visa, sobretudo, a mostrar, através de bons escritores, diversos fenômenos da língua portuguêsa (já explicados, na maioria dos casos, na parte anterior do livro), mas, apesar de ela não pretender dar umas noções sistemáticas da literatura, não nos pareceria inútil completar (numa de certamente muitas edições que o livro, sem dúvida, atingirá, brevemente) o comentário com uma nota, sucinta que fôsse, sôbre o autor do trecho para satisfazer aquêles que por tal informação se interessasisem. O que merece os nossos calorosos elogios é a seleção cuidada e carinhosa que o $\mathrm{A}$. fêz dentre a grande quantidade de textos que deve ter tido a sua disposição. Uma parte integrante do livro e que interpenetra as lúcidas explicações gramaticais, são os exercícios, tão úteis para a revisão da gramática, enriquecimento do vocabulário ou aperfeiçoamento da redação. Foi, também, uma boa idéia que ○ $\mathrm{A}$. teve, completando a sua obra com uma lista, de proveito indiscutivel, de palavras de classificação variável ou difícil e com um pequeno dicionário de sinônimos e antônimos e de definiçōes de palavras menos usuais. Com êsses apêndices torna-se ainda mais prestativa esta obra, cujo caráter e espírito (não deixemos de tornar a salientá-lo) são novos, dando-nos a pressentir que - seu A. contribuirá, através dos seus livros didáticos e através de obras científicas (que são de esperar dêle), para a renovação da filologia brasileira renovação essa que se eștá tornando, nestes últimos tempos, realidade.

Zdenek Hampejs (Praha). 


\section{ELVIRA RINA MALERBI RICCI — BREVE DISCORSO SUCLI ALATI NELLA POESIA PASCOLIANA - Pôrto Alegre, 1959}

In questi ultimi anni s'è scritto diverse cose, in Brasile, su Giovanni Pascoli, grazie alla recente ricorrenza del primo centenario della nascita del celebre poeta romagnolo. L'Autrice del presente volumetto, presentato como tesi per il concorso di Libera Docenza in Lingua e Letteratura Italiana presso I'Università del Rio Grande del Sud, volle dedicare uno studio alla poesia degli uccelli in Giovanni Pascoli. E ciò, ancora una volta, viene a dimostrare la perenne vitalità della poesia pascoliana.

A noi sembra che l'argomento fu ben scelto; difatti il Pascoli molto amore e molta poesia consacrò agli alati cantori. Lo studio tenta "una interpretazione dei simboli racchiusi dal poeta negli alati in generale e in alcuni in particolare", como scrive l'Autrice; ma è anche un "tentativo di lettura condotta fuori di quegli schemi, a cui la scuola ci ha abituati".

In una prima parte, a carattere introduttivo, vien dimostrato como il poeta amò davvero e sempre conversare con gli uccelli, con quelli del giorno e della notte, con quelli che volano alti nel cielo e con quelli che saltellano di ramo in ramo, con quelli che la letteratura d'ogni paese nobilitò e con quelli contro i quali qualche crudele letterato sparò, diciamo cosi, più d'una fucilata.

Vengono successivamente presentati " $i$ prediletti" del poeta: il pittiere, il realino, il cuculo, le rondini, il fringuello, l'allodola e, naturalmente, l'usignolo. Né poteva essere dimenticato il nido, caro agli uccelli come ad ognuno è cara la sua casa, come non potevano essere dimenticati gli sciami cinguettanti lungo le siepi campestri all'alba ed al tramonto.

É un piacere leggere questo volumetto che ci fa riudire, nelle strane e famose onomatopee di pretto gusto pascoliano, il diverso canto di quelle creature che il Leopardi disse essere le più felici del mondo. Si, le più felici del mondo, ma anch'esse con i dolori ed i crucci che gli uomini, questi eterni guastamestieri delle cose, infliggono loro abbattendo con la scure gli alberi dove hanno fatto le loro case, o spaventandole e perfino uccidendole con spari di fucile. E cosi il Pascoli cerca negli uccelli e nei loro destini uno specchio ed un' allegoria onde riflettervi il suo intimo dramma spirituale, fatto di luce e di mistero, di giubilo e di dolore.

Luigi Castagnola.

MADRE M. OLIVIA - ASPECTOS LINCÚíSTICOS DA PONTUAÇÃO - sep. da "Revista de Portugal", série A, L. Port., v. XXIV, pp. 77 a 94, Lisboa, 1959.

E o tema um campo insuficientemente explorado. Não resta dúvida que é importante, muito importante, como qualquer parte da redação. Só aparentemente é bagatela!

Madre M. Olívia, professôra na Faculdade "Sedes Sapientiae" da Pontifícia Universidade Católica de S. Paulo, apresentou um trabalho de valor, resumin- 
do os capitulos com êstes títulos: esbôço histórico; alguns aspectos lingüísticos; uma pontuação expressiva; conclusão.

Sobe de importância o estudo da A. por apresentar alguns exercícios: 1) análise da pontuação numa página de joão de Barros conforme apareceu no século $X V I$, em confronto com uma edição crítica do século $X X ; 2 .{ }^{\circ}$ ) análise da pontuação de um trecho de Garrett.

O trabalho termina com uma bibliografia (p. 95).

Fazemos votos que a $\mathrm{A}$. desenvolva o tema, analisando trechos de escritores nacionais das várias épocas literárias e da atualidade.

R. F. Mansur Guérios.

ARLINDO DE SOUSA - A LÍNCUA PORTUGUESA NO BRASIL - Aspectos léxicos e semânticos, alguns arcaísmos, folclore e linguagem - Editôra Fundo de Cultura, Rio, 1960, 269 pp.

Cresce o número das obras que versam tão atraente assunto - a modalidade lingüística do português americano.

Arlindo de Sousa, tão fértil em temas lingüístico-culturais, apresenta-nos uma obra valiosa, digna da atenção dos curiosos e dos especialistas.

$\mathrm{Da}$ parte introdutora saliento dois pensamentos merecedores de muita atenção. Reproduzi-los-ei sem comentar: "A moderna sociedade brasileira, amálgama de diferentes etnias, está em condiçōes de impor uma diretriz nova à língua portuguêsa". (P. 17).

“O Português do Brasil é a linguagem da tradiçāo portuguêsa, em duas grandes sínteses: o bater do coração medieval e as mãos calejadas dos imigrantes" (P. 29).

Trata, na primeira parte, das fontes de investigação lingüística para o português brasileiro. Numerosos vocábulos apanhados de vários autores são postados, e elucidados muitos quanto ao sentido.

$\mathrm{Na}$ p. 77 há uma novidade referente ao vocábulo carioca. Afigura-se ao A. que Carioca, "assim grafado, aparece como topônimo num documento do século VI; uma paróquia sueva,..." Mas, pergunto eu, não se tratará de homofonia? E a que propósito o Carioca lusitânico foi aplicado no Brasil?

Beiju e mandioca são vocábulos tupis, indiscutivelmente; nãọ são de etimologia desconhecida ou duvidosa. Não será o problema da interpretação que irá destupinizá-los. Ademais, como basium (p. 175) poderia chegar a beiju? Há, ainda, em autores outras formas tupínicas que desmentem a sua procedência européia. E de que jeito os latinos mándere e manducare (p. 175) poderiam criar a mandioca ou a manioca?

Não sei como entender que "as vozes africanas já estão muito estudadas, e, a bem da ciência filológica, vão-se tornando cada vez mais reduzidas" (p. 116). Na verdade, quase nada, infelizmente, quase nada se fêz até agora com 
respeito ao vocabulário afro-negro do Brasil. E será que há nessas linhas do A. um aplauso de "discriminação" lingüistica?

Foram registrados (p. 117 e ss.) numerosissimas expressōes do âmbito da politica nacional que a Lingüistica qualifica de fenômenos da "fala": antes do enfarte, baianada, bem-te-vi, bolāo-de-barro, bolivianizar, esquentar o café etc.

Parece-me que de Dasp se deve ter daspiano (e não daspeano - p. 118), como há garrettiano, shakespeariano, darwiniano, nietzchiano, cavalariano, etc., como de Ipase foi feito ipasiário e năo ipaseário, como de Saps proveio sapiana (que devera ser sapsiana).

Outra observação: balípodo e balipismo, nota 586, da p. 130 , não são da gíria.

Graças à grande influência da cinematografia norte-americana, a vida estadunidense, sua música e novidades fizeram que aqui aportasse, principalmente ao Rio de Janeiro, uma avalanche de expressões anglo-americanas que o A. enfileira no seu ótimo trabalho (da p. 131 a 136). Para alguns exs. estas observações: Jérsei não é sòmente "saia". Jipe não é só carro motorizado do exército. Liderar já consta do "Peq. Voc. Ortogr. da L. Port.", oficial. Impasse talvez seja mais do influxo francês. Ou quei (O. K. de all correct?) parece que não é assim que se ouve, mas òquei, com a vogal inicial aberta. Năo sei o que seja sanduis ou sanduiz, talvez sanduiche? Scotch também se emprega como "uísque". Já vi em jornal carioca escrete, aportuguesamento de scratch. Short não é sòmente "calção curto de banho". O oniônimo Slach, "marca de saia e de veludo", talvez seja o substantivo comum slack(s)? Parece-me que time no exemplo "é possivel... que o foliāo atual, ou melhor, o do time mais novo" deve eqüivaler a "geração", mas näo a "tempo, época". É aportuguesamento de team e não de time. Tweed não é só "marca de lā". Acho que jazebanda e xou são aportuguesamentos por conta do $\mathrm{A}$.

No elenco das francesias, deve ser entendido mixuta como latinismo aproveitado para substituir menu; não é francès. No campo dos galicismos também Portugal é bem aquinhoado (veja-se, p. ex., o "Dic. de Dificuldades da L. Port." por Vasco Botelho do Amarall.

Gueixa é a forma averbada no "Peq. Voc. Ortogr." e não gueicha (p. 139). Sob a forma quibe (e não quíbi - p. 139), êste arabismo recente foi acolhido no "Peq. Dic. Bras. da L. Port."

Em Santa Catarina há Palhoça e não Palhaça (p. 140).

A segunda parte do livro é reservada a "alguns arcaísmos do português do Brasil".

Assistir, na acepçāo de "residir", parece-me que é desconhecido no Brasil. Os exs. de Fr. Vicente Salvador e de Fr. Jaboatão e de outros são espécimes literários verdadeiramente lusitânicos e que, portanto, não têm fôrça probante, como não a têm os exs. de Gândavo respeitante a derradeiro. 
As várias etimologias propostas para enxergar (v. J. Pedro Machado, “Dic. Etim.", s. v. enxerga), Arlindo de Sousa apresenta outra, de um hipotético incericare (p. 179), contra a qual se levanta a grafia tradicional com $\mathbf{x}$. $E$ enxertar já é líquiido e certo o étimo insertare, não se justificando, em consequiência, o encestar (p. 179).

O vocábulo inusitado é expressão da linguagem literária; pouco vale para o tema.

Não se deve levar a sério a origem tupínica de minhoca, proposta por $T$. Sampaio. Há alguns afro-negrismos que foram introduzidos no português lusitânico antes de 1500, graças aos primeiros contactos com a África. Minhoca deve de ser um exemplar.

O verbo mirar, de uso freqüente no Rio Grande do Sul, deve ser explicado por influxo espanhol da fronteira. Estou a favor de Gladstone Chaves de Melo. Ademais, não é popular o verbo português correspondente, nem, tampouco os cognatos mirabolante ( $v$. os dicionários etimológicos), mirada, miradouro, etc. E alguns exs. da toponímia lusa são de procedência germânica Mira, Miral, Mirão, Mirões, Mire, Mirelo, Miro (v. J. M. Piel, “Os Nomes Germânicos na Toponímia Port.", Lisboa, 1936).

Quanto a Odemira, do que consta, p. ex., em J. Leite de Vasconcelos e em Xavier Fernandes, o segundo elemento não é cognato de mirar.

Acrescente-se a sotil (p. 203) o sobrenome Sotil (cp. Miguel Sotil, o descobridor das minas de Cuiabá). A forma sutil não passa de cultismo como o é subtil.

O último capítulo tem por título - folclore e linguagem.

- Vale a pena ler a obra do prof. Arlindo de Sousa - A Língua Portua guêsa no Brasil - que, além de ser um estudo muito bem documentado e rico, diverte com a variedade dêsses documentos. Há riqueza de toponímia, antroponimia, siglas comerciais, industriais, governamentais ou administrativas, políticas, frases-feitas, trovinhas, referências a oniônimos (nomes próprios de produtos comerciais), nomes próprios de edifícios e de casas comerciais, zoonimia (veja-se a vasta lista de hipônimos da p. 128 - 199).

O A., que é natural de Portugal e que vive agora no Brasil, prestou enorme serviço à brasilianidade lingüística.

R. F. Mansur Guérios.

ALBERTINA FORTUNA BARROS E ZÉLIO DOS SANTOS JOTA - VERBOS Editôra Fundo de Cultura, Rio, 1960, 275 pp.

Obra de caráter prático; prestará muito serviço aos estudiosos do Vernáculo. Abrange - conjugação, concordância verbal, emprêgo dos modos e tempos, infinitivo pessoal e impessoal, regência dos principais verbos, pronomes pessoais. 
Algumas observações que me parecem necessárias:

Pág. 17 - Lho é também lhes +0.

Pág. 19 - Não se definiu zeugma; pode perfeitamente elipse aparecer no caso.

P. 20 - nota: É difícil provar dom como espanholismo. A forma dão nada mais é que a pronúncia da forma anterior. Com exceçăo de com e tom, pronuncia-se (é muito comum) /bãu/ bom, / sãu / som, / marrãu / marrom, P./ batãu / batom...

P. 21 - Na série dos pronomes de tratamento, faltou juntar o artigo a senhor e senhora, pois o pronome é o senhor, a senhora, como logo abaixo é citado.

Se bem que sejam oficiais as abreviaturas V. S. ${ }^{\circ}$ e V. Ex. ${ }^{\circ}$, na tradição comercial brasileira só se tem usado V. S., e freqüentissimo, mesmo nas repartições públicas, a abreviatura V. Excia.

P. 30 - Se o tema de estudar é estud, de eserever é eserev, etc., como se poderia entender a vogal temática?

P. 31 - É perfeitamente dispensável a nota 1 , de gramática histórica, referente à queda do -t, e já no latim se verificava o fato.

P. 48 - Não vejo necessidade de separar com designações diferentes tenho de levar, "conjugação obrigatória,", e preciso partir, "expressão verbal". Se lá há obrigatoriedade, aqui há necessidade; a conjugação é, pois, necessitativa.

P. 117 - No período - Pergunte-Jhe se virá - o se é, de fato, conjunção integrante, portanto não pode estar encaixado nas funçōes do se - cuja lição começa destarte: "O se pronome pessoal exerce várias funções,..." Assim também devem ser excluídos os outros exemplos, em que o se é conjunção condicional, causal e concessiva.

P. 193 - Há verbos que se não usam e que foram incluidos (pascer, raer, viger, etc.). Portanto, deveriam ser dadas, na conjugação de jazer, também as formas irregulares.

A obra termina com um indice remissivo.

Parabéns aos professôres Albertina Barros e Zélio dos Santos Jota por essa publicação prática!

R. F. Mansur Guérios.

\section{EVANILDO BECHARA - LIÇōES DE PORTUCUES PELA ANÁLISE SINTÁTICA} Editôra Fundo de Cultura, Rio, 1960, 339 pp.

Eis um livro agradável de se ler! Didático, claro, seguro, rico de ensinamentos, de lições oportunas, enriquecido de observações, mas com 0 inconveniente de näo constar em cada página o número da liçăo correspondente.

Não resta dúvida; se um estudante ou estudioso vier a adquiri-lo, não se arrependerá, estudá-lo-á com proveito. 
É, todavia, insuficiente o exemplo que deu para o predicado verbo-nominal (p. 20).

Se bem que em - Alguém chama o professor lá fora (p. 23) - haja indeterminação, é, contudo, uma indeterminação diferente de - Está ou estão chamando... Por isto, na análise daquele, não se deve qualificá-lo de indeterminado. É o meu parecer!

As combinações pronominais me $+0=$ mo, to $+\mathbf{a}=$ ta, etc., melhor que combinaçōes (p. 43), devem ser chamadas contraçōes.

Acho que haverá alunos que nāo apreenderão com facilidade os exemplos do apôsto especificativo (n. ${ }^{\circ} 5$ - pág. 90).

Ficaria melhor em rodapé o constante nạ p. 101. Trata-se de dissentimento doutrinário.

À p. 109 (n. ${ }^{\circ}$ ) consta, e é verdade, que "a conjunção que liga a [oração] substantiva à oração principal se diz integrante". E logo a seguir: "A nossa língua possui duas conjunções integrantes: que (nas declarações certas) e, se (nas declarações incertas)". Ora, na p. 113 ( $\left.0^{0} 11\right)$ as subordinadas dos exs. Não sabemos quem comprou, não sabemos quanto comprou. etc. são analisadas como orações substantivas, objetivas diretas. Donde se conclui que êsses conetivos são também integrantes; servem para integrar o sentido de outra oração.

Devia o A. encarecer a obra com as célebres palavras denotativas.

Faço aqui ponto final. As observaçōes acima em nada prejudicam o valor da obra, excelente sob qualquer aspecto.

R. F. Mansur Guérios.

ARTUR DE ALMEIDA TÓRRES - MODERNA GRAMÁTICA EXPOSITIVA DA LínGUA PORTUGUESA - Editôra Fundo de Cultura, 11. a ed., Rio, 1960, $320 \mathrm{pp}$.

$O$ advento da nomenclatura gramatical oficial (NGB) proporcionou 0 aparecimento de excelentes manuais como a Pequena Gramática para a Explicação da Nova Nomenclatura Gramatical de Adriano da Gama Kury (em 6.a ed.), 0 Idioma Nacional de Antenor Nascentes (sintese de uma edição anterior, em 4 tomos) e Moderna Gramática Expositiva da Língua Portuguêsa de Artur de Almeida Tôrres. Esta obra teve uma felizarda ocorrência, pois alcançou onze edições até setembro de 1960! Caso virgem na história das gramáticas!

Infelizmente, a NGB não conceituando os têrmos que consagrou, deu azo a que, em vários casos, houvesse mais de uma interpretação. Assim é que na l. a ed. da Moderna Gramática além dos verbos ser e ir, o A. postou outros como anômalos. Assim fiz também no meu despretensioso opúsculo A Nomenclatura Gramatical Brasileira Definida e Exemplificada (Saraiva, S. A., 1960), baseado na observação de que o verbo pôr "constitui anomalia da 2 . $^{\circ}$ conjugaçăo", levado pelo têrmo anomalia que me pareceu em sentido técnico como em verbo anômalo. 
Com Gama Kury reconheço a combinação "quando a preposição permanece íntegra" (ao, pelo) e, "se houver supressão de fonemas", ter-se-á a contração (à, do, no, coa, pro). Mas não assim para Almeida Tôrres, que só admite a contração nos exs. à, às, àquele, àquela, àqueles, àquelas, àquilo. Nos demais casos há combinação.

Outra discordância entre autores pode-se observar na formação do verbo; conceito de verbo primitivo e derivado; verbo composto; etc.

Além do mais, nāo há, na verdade, nenhum autor que siga $100 \%$ a NGB, mesmo que se reconheça nela um mínimo de exigência. P. ex., A. Nascentes conservou em $O$ Idioma Nacional os títulos verbos irregulares fracos a fortes, verbos pronominais (essencialmente pronominais, acidentalmente pronominais), parassíntese, grupos consonânticos.

Igualmente Almeida Tôrres na $11 .^{\circ}$ ed.: derivação sufixal ou progressiva (p. 51), derivaçāo regressiva (p. 52), deverbais (p. 52), justaposiçäo e aglutinação (p. 52), adjetivo restritivo e explicativo (p. 77), gentilicos (p. 78), estrangeirismo (p. 238).

Do exposto se conclui imediatamente que é falha a NCB, e seria de bom alvitre se fizesse uma revisão.

A obra do prof. Almeida Tôrres é clara, concisa e precisa, e, como se trata de gramática expositiva, não incluiu os 34 títulos da NCB referentes à parte histórica.

R. F. Mansur Guérios.

\section{BOLLETTINO DELL' ATLANTE LINGUISTICO MEDITERRANEO - INSTITUTO} PER LA COLLABORAZIONE CULTURALE (FONDAZIONE GIORGIO CINI Centro di Cultura e Civiltà) - Veneza - Roma - n. ${ }^{\circ} 1$ - 1959, 258 pp.

Revista mensal dedicada ao estabelecimento de um atlas lingüístico do Mediterrâneo, cuja idéia surgiu do confronto elaborado, em 1937, por Mirko Deanovic' entre a nomenclatura marinharesca em uso no dialeto sérvio-croato de sua cidade natal, Ragusa, e a terminologia da pesca, recolhida por Alfred Rohe em Grau d'Agde, no Languedócio. Com isso, lançaram-se as bases para a realização de um atlas mediterrânico, fixando-lhe, em grandes linhas, os limites geográficos, a estrutura onomasiológica, os objetivos científicos.

Essas concordâncias lexicais entre línguas de povos diferentes explicam-se pelo fato de que êles se têm servido do mesmo mar, o qual, através dos séculos, tem desempenhado, ininterruptamente, o papel de aglutinador entre as mais diversas etnias, línguas, culturas e tradições. E claro que, em tempos afastados, houve ali uma notável koiné marinharesca. E, entāo, formularam-se perguntas como estas: - Qual a difusão dêsses têrmos? Qual a sua estratificação histórica? Por quais vias êstes têrmos se tornaram patrimônio das populações maritimas? E quais dêles poderiam considerar-se características do ambiente mediterrâneo? Como se exercitou a funçāo unificadora dêsse mar? Claro 
que respostas a tais perguntas só se poderão obter através de uma comparação metódica de materiais, como um atlas lingüístico de novo tipo. E para essa grande tarefa se devotaram vários especialistas. Agora o Bollettino surgiu para "raccogliere la documentazione del lavoro preparatorio compiuto, e costituire insieme la piattaforma per discussioni di metodo e per ricerche storiche e descrittive intorno all' oggetto d'indagine."

Conteúdo dêste n." 1: "Prospettive dell'Atlante Linguistico Mediterraneo" (Mirko Deanovic" — Gianfranco Folena); "I punti di inchiesta"; "Il sistema di traserizione fonetica"; "Il questionario dell" ALM"; "Esperienze ad Otranto col questionario deli' ALM" (Carlo Battisti); "Esperienze nell'Adriatico Orientale col questionario dell' ALM" (Mirko Deanovic); "Terminologia Marinaresca nel Salento (Note Lessicalied Etimologiche) (Gerhard Rohlfs); "A propos de l'atlas linguistique méditerranéen" (Arnald Steiger); "Affinité Linguistique" (André Martinet); “La Préparation des catalogues des noms de poissons et la méthode de la géographie linguistique" (Voimir Vinja); "Alguns derivats del llatí rete en català" (Francese de B. Moll); "Noms de l'alose dans le golfe du lion et migration d'un nom atlantique en Méditerranée" (Louis Michel); "It. Caravella" (B. E. Vidos); "Dal Tirreno all'Adriatico: Considerazioni intorno ad alcuni termini marinareschi" (Giovanni Maver); "Appunti su variazioni ittionimiche in porti vicini della Calabria Tirrenica" (Maria Schiariti); "La coltivazione dei mitili nel lago di Ganzirri (Messina) - Saggio di terminologia" (Oronzo Parlangeli); "Italo-byzantine Etymologies V Avaria "Average" (Henry and Renée Kahane); "L'elemento romanzo nei portolano greci" (Manlio Cortelazzo); "Recensioni"; "Bibliografia"; etc.

R. F. Mansur Guérios.

HEINRICH A. W. BUNSE - ASPECTOS LINGÜISTICO-ETNOGRÁFICOS DO MUNICÍPIO DE SÃO JOSE DO NORTE - Of. Gráf. da Livraria do Globo, S. A., Pôrto Alegre, 1959, 143 pp.

A obra aqui registrada, do romanista Heinrich Bunse, "obedece aos métodos da moderna pesquisa dialectológica, combinando os aspectos linguísticos e etnográficos, critério êste já anteriormente adotado em outros trabalhos do autor, convencido que está da necessidade da pesquisa global por ser o fato lingüístico intimamente ligado ao meio geográfico-histórico e étnico-social."

Tarefa empreendida com muito critério e carinho: a escolha da regiăo para as pesquisas atendeu ao caráter primitivo da mesma - isolamento do elemento humano; fotografias e desenhos para "esclarecer. a relação entre as palavras e as coisas"; obediência a prévio questionário (base no proposto por Serafim da Silva Neto); três viagens com percursos diferentes; inquérito sistemático e outros, especializados.

Preocupado com a coleta de material lingüístico, tarefa "de premente necessidade diante das modificações profundas que estão se processando em todo o Estado", o A. deixou de lado, por ora, qualquer indagação de natureza etimológica. 
Obra bem apresentada que prestará bons serviços para outros investigadores, e, para o caso, fornecerá “os elementos para a elaboraçāo do questionário para o futuro Atlas lingüístico do Rio Grande do Sul, que é a meta final" a que aspira o A., catedrático da Faculdade de Filosofia da Universidade gaúcha.

São outros trabalhos do A.: A Terminologia da Cana de Açúcar no Rio Grande do Sul (sep. da "Rev. Bras. de Filologia", v. 3, t. II, 1947) e Algumas Notas sôbre a Pesca e o Pescador num Trecho do Litoral Sulbrasileiro (sep. da "Rev. Bras. de Filologia", v. 4, t. I e II, 1958).

Como se vê, o A. possui um plano, louvável plano, a que está obedecendo, ao mesmo tempo que serve de estímulo para outros.

Conteúdo do trabalho aqui registrado: Nota preliminar; introduçăo (a fisionomia da região; história do povoamento; o município de São José do Norte); o homem, sentimento religioso e superstiçōes; a habitação; as indústrias caseiras (a tecedeira, o trançador); os meios de transporte; a fazenda (o cavalo, o gado, a ovelha, as lides campeiras); a agricultura (a chácara, a cebola, o milho; a granja de arroz); a pesca; transcrição fonética; linguagem (fonologia, morfologia, formação de palavras, sintaxe e estilo); vocabulário; notas; bibliografia.

R. F. Mansur Guérios.

\section{ÂNCELA VAZ LEÃO - SÓBRE A ESTILISTICA DE SPITZER - Imprensa da Universidade de Minas Cerais, Belo Horizonte s/d [1960].}

Está na moda o estudo da estilistica ou das estilísticas. A A., da Faculdade de Filosofia da Universidade de Minas Cerais, nesse livro sucinto e claro, é também atraída pelo problema, mas delimitado à estilística de Leo Spitzer, que "em sua obra cheia de entusiasmo e conviç̧ão, nos transmite uma doutrina tão original" - "a concepção do estilo como expressão da personalidade do escritor." São títulos das capítulos: situação; princípios e métodos; objeçōes; um trabalho discutivel; nem tudo é desencanto. Conclui a obra com a parte bibliográfica.

Da parte final da obra: "Se nos decidimos a publicar as nossas restrições, fizemo-lo na certeza de que não podem, em nada, atingir o nome do grande romanista. Claro que não podem". E em seguida: "Depois, além da crença na legitimidade de tôda revisão que se faça de boa fẻ, outro motivo nos levou a pôr em letra de fôrma êste trabalho: foi a vontade de cooperar para a difusão dos estudos estilísticos em nossos meios, onde, infelizmente, são quase novidade. Fala-se muito em estilistica porque está na moda. Não raro, porém, se fazem confusões que traem pouca convivência com as fontes."

Fazemos votos que a $A$. continue na trilha, para que se difundam mais êsses estudos fascinantes, mas delicadíssimos a muito complexos.

R. F. Mansur Guérios. 
ALBINO DE BEM VEIGA - VIRGEU DE CONSOLAÇON - Livraria do Globo, S. A., 1959, $170 \mathrm{pp}$.

Edição crítica de um texto arcaico inédito, com introdução, gramática, notas e glossário, é publicação da Universidade da Bahia, mas o A. é catedrático de Filologia Portuguêsa na Faculdade de Filosofia da Universidade do Rio Grande do Sul. Publicou, entre outros trabalhos: O Português do Brasil e a Posição de Silvio Romero na "História da Literatura Brasileira" (sep. da "Provıncia de São Pedro", n. ${ }^{\circ}$ 10, 1947); Confronto de Texto da "História da Literatura Brasileira" (sep. de Veritas, 1955, rev. da Pontifícia Universidade Católica do RS); Programa de Português - Sujeito Inexistente, P. Alegre, 1952; Sugestôes para Unificação da Nomenclatura da Análise Sintática, S. Paulo, 1955; A Filologia no Brasil (sep. do "Boletim do Centro de Estudos Filológicos" da FTURGS, 1955); Ensino e Estudo da Língua Portuguêsa, ed. da Fac. de Filologia da URGS, v. III, 1958.

Graças a denodados trabalhadores (Serafim da Silva Neto, pe. Augusto Magne, Bertil Maler, etc.) vêm surgindo a publicação de manuscritos antigos com que extraordinàriamente se enriquecem os estudos filológicos lusitanos Agora chegou a vez do prof. Albino de Bem Veiga com a edição crítica de Virgeu de Consolaçon. São suas palavras de introdução: "Os códices alcobacenses, hoje arquivados na Biblioteca Nacional de Lisboa, constituem precioso filão para conhecer-se a história cultural portuguêsa em suas origens. A importância avulta não só pela quantidade, pois representa valioso acervo de quatrocentos e tantos manuscritos medievais - a maioria traduçōes de textos latinos, franceses e castelhanos - mas também pelo material inédito que se entesoura naqueles pergaminhos e que, a pouco e pouco, vem iluminando o passado e esclarecendo o presente, em particular no que diz respeito à história da língua portuguêsa. É natural que críticos e filólogos se venham abeberando dessa fonte, cujas edições se revestem de crescente exatidão científica".

São títulos da obra: O códice, a autoria, o confronto dos textos, a edição, a gramática do Virgeu, texto, glossário, elenco dos nomes próprios de pessoa, fontes principais, bibliografia, e corrigenda e acréscimos.

Só nos resta aplaudir o A., e aplaudi-lo incondicionalmente, pois felicíssimo foi na tarefa ingente, e que outros manuscritos de antanho venham à luz do século $X X$ !

R. F. Mansur Guérios.

FRANCISCO CASADO GOMES - CAMONIANA - Coleção de obras téenicas e cientificas da Secretaria de Educação e Cultura do Rio Grande do Sul, Pôrto Alegre, 1958, 144 pp.

"Nosso intuito, diz o A., foi, ao compor êstes comentários, fazer, única e exclusivamente, obra de divulgaçăo junto ao povo brasileiro, e diante de estudantes que, em geral, ligam a obra camoniana à análise..."

"Nunca pretendemos, continua o A., realizar trabalho de erudito... Nosso desejo era mostrar como se poderia ler e comentar a obra camoniana 
sem procurar sujeito e predicado, sem mencionar as oraçōes principais e as secundárias..., e queriamos também - por meio da obra do poeta - homenagear Portugal".

Conteúdo: Como ler Camões; Camões de Ontem e de Hoje; Adamastor; as profecias de Adamastor e Tétis; os dois gigantes; Camōes, a cosmogonia e teorias cosmográficas; a mitologia na lírica camoniana; Camōes e o amor; as "rimas" de Camões; um camonista; Luís de Camōes - o lírico"; "Luis de Camões - o épico"; Camões teatrólogo; "um crítico inédito de Camōes".

Salvo alguns capitulos fracos, a obra merece ampliação e maior divulgação para convencer ou convidar os alunos a ler e a estudar as imortais obras de $\mathrm{Ca}$ mões, dos "Lusiadas" principalmente, e nāo ver nelas períodos para análise sintática, como diz o A. e é fato de há muito tempo. Tenho experiência comigo mesmo. O primeiro contacto que tive com os "Lusiadas" foi através da decomposição sintática, no tempo dos saudosos exames parcelados!

R. F. Mansur Guérios.

\section{ANTENOR NASCENTES - O PROBLEMA DA REGENCIA (Regência Integral a} Viva) - Livraria Freitas Bastos, S. A., Rio - S. Paulo, 1960, 2. ${ }^{a}$ ed., 215 pp.

Não será demais encarecer as obras que versam a regência, e sabem todos as dificuldades freqüentes que assediam principalmente os que escrevem. Louvável foi, portanto, esta $2 .^{a}$ edição que, sob mais de um aspecto, é valiosa, de muita serventia.

$E$ verdade que numerosos títulos constantes na $1 .^{\circ}$ edição deixaram de ter acolhimento nesta nova (abalroamento, abarrotar, abalável, abespinhamento, aborrecimento, aborrecivel, acirramento, acirrar-se, abundância, abundante, acercamento, acanhamento, acanhar, açular, acatamento, acre, etc.), mas em compensação, acrescentados foram outros (abalançar, abandonar, aborrecer, abrigar, acontecer, bater, beber, chorar, cientificas, deferir, degenerar, encadear, enlaçar, etc.) e ainda outros foram enriquecidos de exemplificação no português e no latim, ou, entāo, discutidos com ampliaçāo (crer, cumprir, custar, escapar, assistir, arcar, casar, chamar, conjunto, cuidar, cumprir, custar, dar, deparar, desagradar, dever, enviar, perdoar, pesar, pisar, preferir, etc. )

Eu não morro de amôres pela ortografia oficial, mas eu a sigo porque sou obrigado, por dever de ofício. O A. não a segue, mas não é coerente com a que perfilha. Escreve, à antiga, acceder, accessivel, porém acesso; accrescimo, sem acento, mas crédito (p. 28 s. v. acreditar). Força, subst., p. 23), mas êle (p. 23). Arrogância (p. 23), mas ância (s. v.). E assim por diante. Afinal, isso não deslustra a obra que, certamente, há de ter muita aceitaçāo entre os estudantes e estudiosos.

R. F. Mansur Guérios. 


\section{ERNESTO FARIA - INTRODUÇÃO Ã DIDATICA DO LATIM - Livraria Aca- dêmica, Rio, 1959, 374 pp.}

"Esta publicação, diz o A., é de alguma forma um livro antigo e uma obra nova". Refere-se ao trabalho de 1941 - O Latim e a Cultura Contemporânea que "representou na época o papel de um programa de trabalho a ser cumprido, e de um manifesto especialmente dirigido aos mais novos no exercício do magistério de latim". E refere-se, como obra nova, aos "numerosos acrescentos que the foram feitos", embora houvesse a supressão de alguns capitulos. E foram "especialmente aumentados grandemente o acervo de informações bibliográficas e doutrinárias, pela contribuição da ciência filológica nos anos que se seguiram à primeira publicação".

Sem citar os subtítulos, é êste o conteúdo da prestimosa obra, indispensável aos latinistas patrícios: "A querela dos antigos e modernos"; a crise da cultura; a repercussão no ensino; o latim e a cultura contemporânea; o latim no curso secundário; o texto latino e a edição escolar; a traduçāo e a versão; - estudo gramatical e a orientação lingưística; a aquisição do vocabulário; o comentário; a preparação funcional do professor; indicações bibliográficas.

- A., catedrático da Faculdade Nacional de Filosofia da Universidade do Brasil, completa, com esta publicação, quase trinta e cinco anos de magistério ininterrupto de latim, e nela procurou condensar tôda a sua experiência no ensino dessa disciplina: "Esforçamo-nos, pois, para nêle incluir c que de mais importante nos pareceu haver no que se refere aos problemas das finalidades do seu ensino, bem como os melhores meios de que o professor se possa valer para atingir essas finalidades".

R. F. Mansur Guérios. 